\title{
Amnistia y proporcionalidad desde el punto de vista del Estatuto de Roma en el marco jurídico para la paz en Colombia*
}

\author{
Jean Piero Yani Oñate**
}

Recibido: 30 de noviembre de 2016 • Aprobado: 15 de marzo de 2017

\section{Resumen}

La amnistía o indulto entendida desde el punto de vista del Estatuto de Roma de la Corte Penal Internacional en el marco jurídico para la paz en Colombia, debe contemplar las situaciones que han venido enmarcando el conflicto armado, donde se ha sometido a la población a prácticas como el asesinato, el secuestro, el traslado forzoso de población, la desaparición forzada de personas, el desplazamiento forzado, el ataque generalizado contra la población civil, el terror, la destrucción de bienes y servicios, etc.; con un desarrollo histórico particular. En este sentido, el tema de interés de este artículo se enfoca en responder al cuestionamiento, ¿existe la posibilidad de contemplar la amnistía desde el punto de vista del Estatuto de Roma de la Corte Penal Internacional en el marco jurídico para la paz en Colombia? Teniendo en cuenta la posible salida pacífica del conflicto a través del acuerdo de paz.

En este sentido en el presente artículo se pretende determinar la posibilidad de contemplar la amnistía desde el punto de vista del Estatuto de Roma de la Corte Penal Internacional en el marco jurídico para la paz en Colombia, cuáles son los mecanismos que Colombia debe seguir para que las sanciones penales impuestas con base en un eventual acuerdo de paz entre gobierno y guerrilla de las Farc puedan

"Artículo producto del proyecto de investigación: Amnistía y proporcionalidad desde el punto de vista del Estatuto de Roma en el marco jurídico para la paz en Colombia, para optar al título de magíster en Derechos Humanos y Derecho Internacional de los Conflictos Armados de la Escuela Superior de Guerra. Bogotá, Colombia. DOI: http://dx.doi.org/10.15332/s1900-0448.2017.0047.02

\footnotetext{
** Abogado Universidad Popular del Cesar. Cesar, Colombia. Candidato a magíster en Derechos Humanos y Derecho Internacional de los Conflictos Armados de la Escuela Superior de Guerra. Bogotá, Colombia. Correo electrónico:jyani365@hotmail.com
} 
satisfacer los requerimientos que impone la Corte Penal Internacional frente a la persecución y castigo de los crímenes de lesa humanidad, de guerra y el genocidio. Es importante analizar si el castigo debe ser flexible, severo u olvidado (amnistía e indulto), es decir, es estudiar qué tan positivo puede ser tanto para las personas involucradas o no involucradas en el conflicto adjudicar la amnistía en el acuerdo de paz realizado entre el Gobierno y las Farc.

Palabras clave: Estatuto de Roma, amnistía, indulto, conflicto armado, acuerdo de paz, Corte Penal Internacional.

\title{
Amnesty From the View of the Rome Statute in the Legal Framework for Peace in Colombia
}

\begin{abstract}
The amnesty or pardon understood from the point of view of the Rome Statute of the International Criminal Court in the legal framework for peace in Colombia should contemplate the situations that have been framing the armed conflict, where the population has been subjected to practices Such as murder, kidnapping, forcible transfer of population, forced disappearance of persons, forced displacement, widespread attack on the civilian population, terror, destruction of goods and services, etc.; With a particular historical development. In this sense the topic of interest in this article focuses on answering the question, Is there a possibility of contemplating amnesty from the point of view of the Rome Statute of the International Criminal Court in the legal framework for peace in Colombia? Taking into account the possible peaceful settlement of the conflict through the peace agreement.

It is in this sense that the present article seeks to determine the possibility of contemplating amnesty from the point of view of the Rome Statute of the International Criminal Court in the legal framework for peace in Colombia, which are the mechanisms that Colombia must follow That the criminal sanctions imposed based on a possible peace agreement between the Farc government and guerrilla can meet the requirements imposed by the International Criminal Court in the face of the persecution and punishment of crimes against humanity, war and genocide. It is important to analyze whether the punishment should be flexible, severe or forgotten (amnesty and pardon), to study how positive it may be for both
\end{abstract}


the persons involved and not involved in the conflict to award the amnesty in the peace agreement between the Government and the Farc.

Keywords: Rome Statute, Amnesty, Pardon, Armed conflict, Peace agreement, International Criminal Court.

\section{Anistia e proporcionalidade desde o ponto de vista do Estatuto de Roma no marco jurídico para a paz NA Colômbia}

\section{Resumo}

A anistia ou indulto entendida desde o ponto de vista do Estatuto de Roma da Corte Penal Internacional no marco jurídico para a paz na Colômbia deve contemplar as situações que tem acontecido no conflito armado, no qual a população tem sido submetida a praticas como: o assassinato, o sequestro, o traslado forçoso da população, a desaparição forçada de pessoas, o deslocamento forçado, o ataque generalizado contra a população civil, o terror, a destruição de bens e serviços, etc; com um desenvolvimento histórico particular. Neste sentido, o tema de interesse deste artigo foca-se em responder a pergunta: existe a possibilidade de contemplar a anistia desde o ponto de vista do Estatuto de Roma da Corte Penal Internacional no marco jurídico para a paz na Colômbia? Levando em consideração a possível finalização pacífica do conflito através do acordo de paz.

Neste sentido no atual artigo pretende-se determinar a possibilidade de contemplar a anistia desde o ponto de vista do Estatuto de Roma da Corte Penal Internacional no marco jurídico para a paz na Colômbia, quais são os mecanismos que a Colômbia deve seguir para que as sanções penais impostas baseadas em um eventual acordo de paz entre o governo e a guerrilha das Farc possam satisfazer os requerimentos que impõe a Corte Penal Internacional no relacionado com a perseguição e punição dos crimes contra a humanidade, de guerra e o genocídio.

É importante analisar se a punição deve ser flexível, severa ou esquecida (anistia e indulto), aliás, estudar que tão positivo poder tanto para as pessoas envolvidas ou não envolvidas no conflito adjudicar a anistia no acordo de paz realizado entre o governo e as Farc.

Palavras-chave: Estatuto de Roma, anistia, indulto, conflito armado, acordo de paz, Corte Penal Internacional. 


\section{Introducción}

El tema que se desarrollará a lo largo de este artículo se enfoca en analizar la posibilidad de contemplar la amnistía desde el punto de vista del Estatuto de Roma de la Corte Penal Internacional en el marco jurídico para la paz en Colombia, teniendo en cuenta que Colombia hizo la adhesión a las premisas jurídicas planteadas por la Corte Penal internacional (CPI), enfocándose en tener en cuenta la gran cantidad de conductas vulneradoras de los derechos humanos que se han dado en el contexto de violencia que ha atravesado Colombia por años y que aún sigue afrontando.

Es así como se crea el marco jurídico para la paz, el cual se plantea con la finalidad de abrir un espacio constitucional para el desarrollo de una estrategia integral y coherente de justicia transicional que permita la máxima satisfacción posible de los derechos de las víctimas y la transición hacia una paz estable y duradera. La reforma retoma la paz como finalidad prevalente de los instrumentos de justicia transicional. Así mismo, mediante el Acto Legislativo 01 de 2012 se formula la ley para la creación de una comisión de la verdad, ley estatutaria para determinar criterios de selección para la investigación de los máximos responsables de los más graves crímenes, y ley estatutaria para determinar qué delitos se consideran conexos al delito político, leyes que sustentan el marco jurídico para la paz.

Colombia en este caso como Estado parte de lo planteado por la Corte Penal Internacional en el Estatuto de Roma, asumiendo su aceptación frente a la puesta en marcha de acciones relacionadas con los valores de justicia y paz, los cuales deben ser coherentes con la justicia penal y sus presupuestos frente al manejo de delitos de lesa humanidad como muchos ocurridos durante el conflicto armado.

En este sentido, se analizará el aspecto específico de la amnistía e indulto, exactamente si es posible o no concederlo a la luz del Derecho Penal Internacional. Se retomará la situación/contexto o realismo político que se ha venido decantando desde las leyes de transición en el país, desde la Ley 975 de 2005 y el llamado marco jurídico para la paz, haciendo algunas comparaciones con modelos de otros países donde ya se han reconocido la justicia transicional como lo fue en Sudáfrica, Chile, Brasil, Argentina, finalmente, el último tema a tratar del presente artículo será el de la tesis central, que abarca este mismo propósito pero a profundidad, donde expondremos con mayor exactitud el gran problema de afrontar un proceso 
de justicia y paz, y el del marco jurídico para la paz que se avecina con el momento y a las realidades políticas en la que estamos.

En esta medida vale la pena aclarar que esta problemática no es nueva, no obstante, se ha evidenciado que existen muchos vacíos para lograr una reparación integral en cuanto al daño que han sufrido las víctimas de delitos de lesa humanidad. En este sentido el cuestionamiento investigativo que surge es, ¿existe la posibilidad de contemplar la amnistía desde el punto de vista del Estatuto de Roma de la Corte Penal Internacional en el marco jurídico para la paz en Colombia?

\section{Diseño metodológico}

Para la realización del trabajo se llevó a cabo un análisis del Estatuto de Roma y el marco jurídico para la paz y de sus decretos reglamentarios, como también se observaron las conclusiones de entidades gubernamentales que realizan seguimiento al cumplimiento de lo ratificado en el Estatuto durante el proceso de paz. Como herramientas se acudió a la revisión documental de la Ley 975 de 2005, también al análisis de las sentencias proferidas por los juzgados especializados en acuerdos de paz durante el conflicto armado.

\section{Antecedentes históricos}

\section{Conflicto armado en Colombia}

El conflicto armado en Colombia proviene de fenómenos sociales e históricos que han traído duras repercusiones tanto al Estado como a la población, por ello es sumamente importante entrar a analizar cómo se ha dado el conflicto a través de la historia. De igual forma el conflicto se relaciona directamente con las marcadas inequidades que dejó la violencia bipartidista, la cual se caracterizó específicamente por la tenencia de poder y lucha de tierras.

En este sentido, el conflicto colombiano se puede entender como un conflicto armado interno que se desarrolla desde hace más de 50 años, pasando por una serie de etapas que tienen su antecedente histórico en la violencia bipartidista que sin duda se evidencia en la década de los años 50, pero que al fin y al cabo era el resultado del comportamiento de los dos partidos durante la primera mitad del 
siglo XX, en el que acentuaron su antagonismo a partir de la Guerra de los Mil Días, dualidad de partidos que representaban de forma muy parcial los intereses de la población, siendo esta la principal circunstancia que ha actuado como el hilo conductor que ha hilvanado los diferentes hechos de violencia.

Es importante aclarar que el conflicto armado comprendió varias etapas a través de la historia que provienen y están enmarcadas en la violencia bipartidista. En esta medida se identifican cuatro periodos en los cuales se ha desarrollado el conflicto armado colombiano:

El primer periodo (1958-1982) marca la transición de la violencia bipartidista a la subversiva, caracterizada por la proliferación de las guerrillas que contrasta con el auge de la movilización social y la marginalidad del conflicto armado (Centro Nacional de Memoria Histórica, 2001). Este periodo corresponde a una época donde se presentaron ciertos incidentes de violencia política constantes en diversas regiones.

El liberalismo en el poder a partir del año 30, trató de ganarse la fuerza pública para imponer en algunas regiones su mayoría electoral o para defenderla. Los conservadores no estaban dispuestos a perder en las urnas lo que habían ganado con las armas en la Guerra de los Mil Días. Usaron las dos formas y añadieron una tercera muy poderosa: la fuerza de la Iglesia católica. El liberalismo apeló a encabezar luchas agrarias como apoyo político. El Partido Comunista tomó el mismo camino. De tal suerte que armas, presupuesto nacional, ideología y tierra, es decir, todas las formas de lucha, se convirtieron en la mezcla explosiva que llamamos La Violencia -1925 y 1955-. Gaitán representó las aspiraciones populares y Laureano Gómez las del establecimiento. Entre esas fuerzas el choque era inevitable. El Partido Conservador se propuso inhibir por medio del terror al liberalismo para recuperar el poder (Molano, 2010).

Durante esta etapa logran evidenciarse dos cambios bruscos en la hegemonía política, en 1930 surgió la división del partido gobernante entre dos candidatos: Guillermo Valencia y Alfredo Vásquez Cobo, lo cual le facilitó al candidato Enrique Olaya Herrera acceder al poder, aun siendo una fuerza minoritaria, hecho que generó violencia la cual el país vivió dos décadas después debido a la violencia sectaria por parte de los seguidores del partido derrotado, provenientes de Boyacá $\mathrm{y}$ los dos santanderes.

El segundo periodo (1982-1996) se distingue por la proyección política, expansión territorial y crecimiento militar de las guerrillas, el surgimiento de los grupos 
paramilitares, la crisis y el colapso parcial del Estado, la irrupción y propagación del narcotráfico, el auge y declive de la Guerra Fría junto con el posicionamiento del narcotráfico en la agenda global, la nueva Constitución Política de 1991 y los procesos de paz y las reformas democráticas con resultados parciales y ambiguos (Uprimmy, 2005, p. 34).

Esta etapa se caracterizó por un mayor recrudecimiento el cual ocurrió en 1988, cuando estaba en la presidencia Virgilio Barco y se rompieron los diálogos de paz con las guerrillas.

Iniciando la década de los años 80 y sobre el transitar de 1983, las Fuerzas Revolucionarias de Colombia (Farc) se sentaron por primera vez con el presidente Belisario Betancur a hablar de paz, en esta mesa se logró una tregua en el conflicto armado, pero luego de algunos enfrentamientos que se venían presentando entre esta insurgencia y las fuerzas militares, conllevó a la reactivación de las hostilidades. Así mismo, en 1985 se presenta un hecho muy lamentable y representativo en la historia del país, la toma del Palacio de Justicia por parte de la guerrilla del M-19, marcó la mente de muchos colombianos de la época, dicha toma terminó con 95 personas muertas y más de un centenar de desaparecidos.

El tercer periodo (1996-actualiadad) marca el umbral de recrudecimiento del conflicto armado. Se distingue por las expansiones simultáneas de las guerrillas y de los grupos paramilitares, la crisis y la recomposición del Estado en medio del conflicto armado y la radicalización política de la opinión pública hacia una solución militar de dicho conflicto. La lucha contra el narcotráfico y su imbricación con la lucha contra el terrorismo renuevan las presiones internacionales que alimentan el conflicto armado, aunado a la expansión del narcotráfico y los cambios en su organización (LLorente, Escobedo, Echandía, Rubio, 2002, p. 14).

Este periodo marca el reacomodo del conflicto armado. Se distingue por una ofensiva militar del Estado que alcanzó su máximo grado de eficiencia en la acción contrainsurgente, debilitando pero no doblegando la guerrilla, que incluso se reacomodó militarmente. Paralelamente se produce el fracaso de la negociación política con los grupos paramilitares, lo cual deriva en un rearme que viene acompañado de un violento reacomodo interno entre estructuras altamente fragmentadas, volátiles y cambiantes, fuertemente permeadas por el narcotráfico, más pragmáticas en su accionar criminal y más desafiantes frente al Estado (Uprimmy, 2005, p. 45).

Se puede percibir que el principal motivo de generación de violencia a lo largo del tiempo se da en el proceso de la lucha por el poder político, donde tanto el 
Gobierno como los grupos guerrilleros pretenden alcanzarlo, generando a su vez el crecimiento de guerrillas, surgimiento de grupos paramilitares, narcotráfico y altos flagelos contra la población, propiciando el despojo de tierras y el desplazamiento; sin embargo, a lo largo del tiempo se han buscado alternativas especializadas en disminuir la violencia y lograr acuerdos que favorezcan al país en general, por esto la importancia de analizar el contexto histórico de las conversaciones de paz que se han presentado en diferentes momentos de la historia de Colombia.

\section{Conversaciones y negociaciones de paz}

Así como el conflicto armado en Colombia es el resultado de hechos históricos que han marcado la violencia actual, simultáneamente se han generado procesos de paz los cuales tienen su origen en la segunda mitad del siglo XX, cuando una serie de hechos marcaron el rumbo que tomaría el país y serían el inicio de una época de violencia generalizada.

Es así como a raíz de la lucha bipartidista entre liberales y conservadores, el asesinato de Jorge Eliecer Gaitán marcó el inicio del terrorismo tanto en el espacio urbano como en el rural, el nacimiento de grupos al margen de la ley, así como guerrillas liberales y comunistas. En relación con lo anterior, en 1953 el general Gustavo Rojas Pinilla asume la presidencia tras un golpe de Estado, y es durante su mandato que se produce la primera amnistía en la que cientos de guerrilleros liberales del llano entregaron sus armas bajo el mando de Guadalupe Salcedo.

A raíz de lo anterior nace el Frente Nacional en 1958, con el fin de buscar alternativas para las negociaciones de paz y darle fin al conflicto, el mecanismo que se pretendía utilizar era turnarse la presidencia durante los próximos dieciséis años, lo cual no tuvo buenos resultados:

Por su naturaleza excluyente y las pugnas por la posesión de tierras ocasionaron el surgimiento de los principales grupos guerrilleros como las Fuerzas Armadas Revolucionarias de Colombia - Farc, el Ejército de Liberación Nacional - ELN, el Ejército Popular de Liberación - EPL y el Movimiento 19 - M-19 (LLorente, 1999, p. 22).

Debido al surgimiento de estas guerrillas, durante el gobierno de Belisario Betancur se busca implementar un proyecto de amnistía, que con el tiempo y su 
impulso se convirtió en ley, que apuntaba a la desmovilización de los grupos guerrilleros que habían surgido, lo cual permitiría un acercamiento con los miembros de los grupos, con el fin de establecer una paz negociada para lo cual se crea una comisión de paz para llevar a cabo las conversaciones.

El 28 de marzo de 1984 en el municipio de La Uribe-Meta, la Comisión de Paz formada por el Gobierno de Betancur selló el primer acuerdo de cese al fuego con las Farc. El compromiso buscaba promover la modernización de las instituciones, fortalecer la democracia y establecer las garantías para ejercer la actividad política por parte de los integrantes de la guerrilla (Pardo, 2004, p. 25).

Es de suma importancia reconocer que durante esta época nace la Unión Patriótica, la cual se crea como un partido político de las Farc, dicha unión se integró por estudiantes inconformes con el sistema educativo, comunistas inconformes con el gobierno y miembros de grupos indígenas que no sentían sus derechos reconocidos, no obstante, la unión no perduró puesto que los sectores de la élite radical del país lo quebrantaron poco a poco.

En 1984 el M-19 se alió con el EPL para llevar a cabo negociaciones con el Gobierno de manera conjunta. Los diálogos se establecieron en E1 Corinto (Cauca) y El Hobo (Huila) y concluyeron en un acuerdo firmado el 24 de agosto de 1984 en el cual se establecía el cese al fuego (Pardo, 2004, p. 25).

Como se evidencia, se dieron fuertes intentos de conversaciones, treguas y acuerdos que buscaban la paz, sin embargo estos nunca prosperaron y se finiquitaron a mediados de 1985, debido a que los grupos guerrilleros no sentían una corresponsabilidad del Gobierno en sus requerimientos y no ofrecían las garantías reales para su resocialización a la población civil, sin tener fuertes represalias por parte de otros grupos al margen de la ley que se pudieran presentar.

Otro hecho importante en la historia de las negociaciones de paz fue la llamada Iniciativa para la paz en 1990, la cual buscaba la desmovilización de los grupos guerrilleros M-19 y EPL. Así mismo el gobierno de César Gaviria le apunta al desarrollo de la Asamblea Nacional Constituyente, la cual buscaba posibilitar nuevas negociaciones que no se dieron debido al bombardeo de la Casa Verde, el principal asentamiento de las Farc, lo cual ocasionó fuertes episodios de violencia. 
Según lo afirmado por Fernández (2015), entre abril y junio de 1992 el Gobierno estableció las negociaciones de paz con la Coordinadora Guerrillera Simón Bolívar (conformada por las Farc, ELN y el EPL) en Tlaxcala, México. La agenda abarcaba diez puntos, sin embargo, tras el secuestro y posterior muerte del exministro Argelino Durán por parte de guerrilleros del EPL, los diálogos llegaron a su fin el 4 de mayo de 1992.

Durante el gobierno de César Gaviria se logran acuerdos con el Partido Revolucionario de los Trabajadores (PRT), el Movimiento Indígena Armado "Quintín Lame”, una fracción del ELN y el EPL, sin lograr lo mismo con las Farc, quienes continuaron su lucha armada. Durante el gobierno de Andrés Pastrana, quien fue presidente entre 1998-2002, se alcanzó el primer diálogo formal con las Farc, encaminando desde el inicio su política de Gobierno hacia la búsqueda de la paz, denominado el Proceso de Paz del Caguán.

\footnotetext{
Durante el llamado Proceso de Paz del Caguán se creó una zona de distención en la cual fueron despejados 42.000 kilómetros cuadrados que equivalían a cinco municipios del Meta y Caquetá (San Vicente del Caguán, La Macarena, Uribe, Mesetas y Vista Hermosa). La agenda acordada contenía diez puntos y fue llamada "Política de paz para el cambio", en ella se contemplaban temas sobre derechos humanos, reformas políticas y agrarias, paramilitarismo, derecho internacional humanitario, entre otras (Fernández, 2015, p. 45).
}

Aunque se esperaba mucho del Proceso de Paz del Caguán, este no contó con la rigurosidad, regularidad y organización necesaria, puesto que hubo una fuerte improvisación del Gobierno y falta de disposición de las Farc. Estos hechos agudizaron la violencia generando acciones terroristas como secuestros, extorsiones, asesinatos y ataques a la población civil, llevando al fin de las conversaciones debido al asesinato del congresista Luis Eduardo Gechen.

De otro lado, Álvaro Uribe Vélez asume la presidencia implementando la política de seguridad democrática. Durante su mandato se celebran negociaciones y acuerdos con los grupos paramilitares del país, tras la promulgación de la ley de justicia y paz en el 2005, se inicia la desmovilización de alrededor 30.000 integrantes de las Autodefensas Unidas de Colombia - AUC y la entrega de los principales jefes paramilitares (Huila, 2016). Durante este gobierno no se evidencian fuertes 
acercamientos entre el gobierno y las Farc y se intentó negociar con el ELN pero no hubo discrepancia con el Gobierno.

En el 2012, durante el gobierno de Juan Manuel Santos se inicia un proceso formal de diálogos y negociaciones con las Farc, mediante la promulgación de la ley de víctimas y restitución de tierras, el Gobierno manifestó a la guerrilla su intención de retomar las discusiones, lo cual derivó en una serie de comunicaciones secretadas por medio de recados entre la subversión y el Gobierno. Dichas conversaciones dieron lugar al establecimiento de reuniones presenciales en La Habana, teniendo como resultado el Acuerdo para la terminación definitiva del conflicto firmado en Bogotá el 24 de noviembre de 2016.

Los puntos en discusión que se buscaban aprobar mediante el acuerdo se enfocaron en: política de desarrollo agrario, participación política, fin del conflicto, solución al problema de las drogas ilícitas, víctimas y mecanismos de refrendación de los acuerdos. Estos puntos fueron refrendados, según la ley debía realizarse en un plebiscito en el que los ciudadanos debían votar SÍ o NO al acuerdo. El resultado final fue una victoria para el NO (López y Cueter, 2016).

El resultado del plebiscito obligó al Gobierno a renegociar el acuerdo, tomando en consideración las objeciones de los opositores, a la vez que creó incertidumbre sobre la aplicación legal de los acuerdos. Tras un periodo de negociación con los promotores del NO el Gobierno y las Farc acordaron un nuevo texto para el acuerdo de paz, el cual se firmó el 24 de noviembre en el Teatro Colón de Bogotá. Este nuevo acuerdo fue ratificado por el Senado de Colombia y la Cámara de Representantes el 29 y 30 de noviembre.

Posterior a esto se promulgó el Acto Legislativo 01 de 2016 o Acto Legislativo para la Paz, el cual busca actualmente implementar rápidamente el acuerdo al que llegara el Gobierno con las Farc en La Habana.

Las conversaciones y negociaciones de paz han estado sujetas a lo largo del tiempo a los intereses tanto del Gobierno de turno como a los de los grupos al margen de la ley, los cuales condicionan si se llevan a cabo los acuerdos o no. No obstante, es de recalcar el papel tan importante que ha ejercido el Gobierno en diferentes administraciones por alcanzar la paz y establecer enlaces con los grupos al margen de la ley, con el fin de sentarse a negociar y llegar a acuerdos que beneficien a todos en igual proporción, incluida a la población civil.

En este sentido, el Gobierno actual a cargo del presidente Juan Manuel Santos es quien más ha logrado en cuanto a los acuerdos con grupos al margen de la ley 
en la búsqueda de una paz negociada, puesto que se han tenido en cuenta los dos puntos de vista de cada una de las partes buscando marcadas concordancias. Sin embargo, es de suma importancia tener en cuenta los acuerdos que involucran a las víctimas directas y de qué manera se penalizan jurídicamente los delitos de lesa humanidad, como el sometimiento a la población civil a prácticas como el asesinato, el secuestro, el traslado forzoso de la población, la desaparición forzada, el desplazamiento forzado, el ataque generalizado contra la población civil, el terror, la destrucción de bienes y servicios, etc.

\section{Elementos jurídicos para la reconstrucción de la paz}

\section{Marco internacional}

A nivel internacional es necesario hacer mención al Estatuto de Roma, que se promulga con el fin de dar un reconocimiento a los derechos de niños, mujeres y hombres que han sido víctimas de atrocidades y crímenes que constituyen una amenaza para la paz, la seguridad y el bienestar de la humanidad.

La primera y segunda guerra mundial ocurridas en el siglo XX representan dos momentos en la historia en los cuales la humanidad ha sufrido flagelos de gran magnitud y crueldad que implicaron graves violaciones a los derechos humanos de millones de mujeres, niños, jóvenes y ancianos, pero para el momento en que ocurrieron estas guerras, y por consiguiente al momento de asumir por parte de los Estados vencedores la función de juzgamiento de quienes habían incurrido en la violación de derechos humanos cometiendo crímenes de lesa humanidad, genocidio, crímenes de guerra y de agresión, no existía un tribunal penal previamente constituido así que se crearon tribunales ad hoc.

El Estatuto de Roma permite autorizar a un Estado Parte a intervenir en una situación de conflicto armado o en los asuntos internos de otro Estado, con el fin que se cumpla el respeto por los derechos humanos y a su vez garantizar que la justicia internacional sea respetada y puesta en práctica en forma duradera (Guerrero, 2006).

Es así como nace la Corte Penal Internacional, la cual es de carácter permanente, independiente y vinculado con el sistema de las Naciones Unidas, tiene competencia sobre los crímenes más graves de trascendencia para la comunidad internacional en su conjunto. 
Conviene distinguir el papel que ocupa la Corte Penal Internacional en la reconstrucción de la paz, puesto que es un ente que se encarga de juzgar a las personas que han cometido crímenes de genocidio, de guerra y de lesa humanidad, en este sentido su objetivo principal es ejercer la jurisdicción sobre las personas que hayan cometido los crímenes más graves de trascendencia internacional.

Ahora bien, Colombia dentro del camino que ha llevado en la reconstrucción de la paz no ha sido ajeno a la intervención de la Corte Penal Internacional en las negociaciones del gobierno colombiano con las Farc en una búsqueda de año tras año de la paz. Es así como la competencia que dé la Corte Penal Internacional:

Se circunscribe a los crímenes de genocidio, de lesa humanidad, de guerra y de agresión, y procede en casos en que la justicia penal internacional debe completar o corregir irregularidades presentadas durante el enjuiciamiento de los responsables o entrar a sustituir la justicia nacional por su negligencia o falta de capacidad o de voluntad para hacer comparecer a los responsables ante la justicia (Centro Nacional de Memoria histórica, 2013).

Es interesante analizar la competencia de la Corte Penal Internacional en la lucha contra la impunidad de estos delitos de lesa humanidad, puesto que de no existir la Corte Penal Internacional que establezca la responsabilidad internacional a nivel individual en crímenes graves contra la humanidad, muchos delitos quedarían impunes.

En las últimas décadas se han cometido graves crímenes contra la humanidad sin haber logrado responsabilizar penalmente a ningún individuo por tales crímenes, tal es el caso de Camboya, Mozambique, Liberia, El Salvador, Argelia, la región de los Grandes Lagos de África y otros países (Naciones Unidas, 2007).

Igualmente, su importancia también es a nivel procesal, como lo indican las Naciones Unidas (2007):

El establecimiento de un tribunal permanente para castigar a los responsables de crímenes de guerra, crímenes de lesa humanidad y genocidio, evita los retrasos inherentes de preparar un tribunal ad hoc que puede ser aprovechado por los criminales para escapar o desaparecer; los testigos pueden ser intimidados (párrafo 11). 
Así, la Corte Constitucional ha recurrido a esos conceptos como fundamento normativo para tomar determinaciones tan importantes en materia penal, como las relativas al alcance de la obediencia debida por parte de los militares, o aquellas relativas a los derechos de las víctimas de los delitos.

Ese contexto, el Derecho Internacional Humanitario (DIH), no solo permite sino que incluso obliga a interpretar los alcances del Derecho a partir de las garantías fundamentales previstas no solo en la Constitución sino también en muchos Tratados de Derechos Humanos del Derecho Internacional Humanitario (DIH). La Corte Penal Internacional, es un Tribunal de Justicia internacional permanente cuya misión es juzgar a las personas que han cometido crímenes de genocidio, de guerra y de lesa humanidad (Guerrero, 2006, p. 4).

En el plano internacional, tales mecanismos incluyen tanto mecanismos jurídicos formales como estudios e informes de monitoreo que, aunque desprovistos de valor jurídico preciso, constituyen importantes herramientas políticas, jurídicas y diplomáticas, evaluación y seguimiento de la situación de derechos humanos en un país determinado.

Es necesario perseguir y castigar a los responsables de los crímenes como el genocidio, ya que la Corte Internacional de Justicia se ocupa de casos entre Estados e individuos. Los derechos humanos, son aquellos que el hombre posee por el simple hecho de serlo, son inherentes a la persona y se proclaman sagrados, inalienables, imprescriptibles, fuera del alcance de cualquier poder político (Delvecchio, 1959).

Estos informes de la comunidad internacional usualmente incluyen un análisis de la situación de derechos humanos, incluso en países con tradiciones garantistas robustas. En ese sentido, la Constitución Política de 1991, estableció que las autoridades están instituidas para proteger a todas las personas residentes en Colombia en su vida, honra, bienes, creencias y demás derechos y libertades y para asegurar el cumplimiento de los deberes sociales del estado y de los particulares (Constitución Política de Colombia, 1991). Sin embargo, los organismos internacionales de protección de derechos humanos han manifestado permanentemente su preocupación por los altos índices de violación de los mismos. 
Comparados con otros delitos, las violaciones a los derechos humanos exhiben niveles de impunidad mayores, tal situación de por sí se traduce en el incumplimiento de obligaciones internacionales contraídas por el Estado que se concretan en garantizar a las víctimas los derechos a un recurso judicial efectivo, a la verdad, a la justicia y a la reparación y en proporcionar garantías de no repetición. La situación de impunidad tiene efectos muy graves ante el DIH, ya que ha sido considerada causa y consecuencia de la violencia, debido a que el deterioro del monopolio estatal de la fuerza y la creciente desconfianza en el sistema judicial incentivan a los ciudadanos a acudir a mecanismos o grupos de justicia privada, desestimulando a los denunciantes y contribuyendo a la reiteración de conductas violatorias de los derechos humanos.

Sin una Corte Penal Internacional que trate la responsabilidad individual en los actos de genocidio y las violaciones graves de derechos humanos, estos delitos quedan a menudo impunes, lo que se pretendería que no sucediera actualmente en Colombia en los acuerdos de paz con las Farc. En los últimos 50 años, ha habido muchos casos de crímenes contra la humanidad y crímenes de guerra en los que ningún individuo ha sido castigado, ¿̨pero qué pasaría si la Corte Penal Internacional considerara la amnistía como una salida notable para los acuerdos.

\section{Marco nacional}

A nivel nacional, en concordancia con la postulación de elementos jurídicos que favorezcan la reconstrucción de la paz, se formula el Marco Jurídico para la Paz, planteado con la finalidad de abrir un espacio constitucional para el desarrollo de una estrategia integral y coherente de justicia transicional, que permita la máxima satisfacción posible de los derechos de las víctimas y la transición hacia una paz estable y duradera (Paz, 2013). El marco jurídico para la paz contiene unas disposiciones específicas en materia de investigación y atribución que no siguen las lógicas tradicionales de investigación y judicialización.

El Marco Jurídico para la Paz y su ley estatutaria para la ejecución de penas se desarrolla a partir de la Sentencia C-577 de 204, en la cual se especifica que en primer lugar la Constitución Política de Colombia tendrá un nuevo artículo transitorio que será el 66, dentro del cual se plantean: 
La excepcionalidad de los instrumentos de justicia transicional y que tendrán como finalidad prevalente facilitar la terminación del conflicto armado interno y el logro de la paz estable y duradera, con garantías de no repetición y de seguridad para todos los colombianos; y garantizarán en el mayor nivel posible, los derechos de las víctimas a la verdad, la justicia y la reparación (Corte Constitucional, 2014).

Vale la pena aclarar que dentro de lo contemplado en este artículo no se tuvo en cuenta la vinculación de lo ratificado en el Estatuto de Roma de la Corte Penal Internacional, el cual afirma que:

Comparados con otros delitos, las violaciones de los derechos humanos exhiben niveles de impunidad mayores, tal situación de por sí se traduce en el incumplimiento de obligaciones internacionales contraídas por el Estado que se concretan en garantizar a las víctimas los derechos a un recurso judicial efectivo, a la verdad, a la justicia y a la reparación, y en proporcionar garantías de no repetición (Naciones Unidas, 2007).

La justicia es entendida desde dos puntos de vista: justicia penal tradicional y justicia transicional, o también como los mecanismos que han sido implementados hasta la fecha y que han recibido esa caracterización. En cuanto a la justicia penal tradicional el Ministerio de Justicia (2014) encontró que existe lo siguiente:

Un déficit por parte de los participantes en recursos y capacidad institucional que hace dudar que la administración de justicia pueda enfrentar el reto de judicializar a quienes se desmovilicen de manera masiva, sin desconocer la importancia de la justicia penal en el marco de la transición hacia la paz, esa ineficacia del sistema penal general desconfianza y una sensación de impunidad entre los participantes (Ministerio de Justicia, 2014).

Al indagar por el sentido y alcance de la justicia transicional, nos encontramos con comprensiones casi unánimes entre los participantes en el proceso de paz sobre la justicia como un concepto amplio y abarcador que no puede reducirse a su componente penal. La cuestión de la justicia en la transición política va mucho más allá de la investigación y atribución de la responsabilidad penal. Desde su perspectiva, la justicia en este contexto corresponde en muy buena medida con la justicia social. 
En el marco de un acuerdo de paz, debe contemplar las causas estructurales del conflicto, pues se tiene anclado y entrelazado el concepto de justicia como cárcel punitiva, es decir la justicia transicional no ha sido lo suficientemente comprehensiva de la dimensión social de la justicia, pues una solución negociada del conflicto armado debe tener en cuenta las causas del conflicto, de lo contrario el acuerdo de paz no garantizará la no repetición de las conductas violentas (Ministerio de Justicia, 2014).

En este sentido, es importante considerar que la justicia contemple no solo la justicia penal, sino la recuperación emocional de las víctimas y su rehabilitación integral. Las víctimas deben ser un foco de apoyo por parte del Estado, dentro de los acuerdos de paz.

En cuanto a las sanciones, más que hablar de cárcel o no cárcel, es necesario entrar a analizarlas desde la amnistía e indulto contemplando los procesos más complejos como son la resocialización, la reintegración y la recuperación emocional tanto de las víctimas como de los victimarios. De igual manera, el Estado debe reconocer y aclarar su responsabilidad, brindando medidas de seguridad y protección suficiente, pertinente y oportuna para poder participar en cualquier mecanismo de participación, ya sea judicial o extrajudicial.

Como lo expresa Cortes (2016), lo anterior supone:

Reflexionar sobre los costos de la paz y el posconflicto en Colombia y la preocupación por la concreción o materialización real de los derechos humanos y la atención a grupos marginados. Dicha materialización se realiza mediante la adopción de políticas públicas con perspectiva de derechos y con amplia participación de la sociedad civil; de esta manera, los derechos humanos se convierten en el referente y fin último para las políticas públicas en materia de posconflicto. Y estas, a su vez, en el instrumento o medio idóneo para su realización (pp. 129-145).

\section{Amnistía o indulto desde el punto de vista del Estatuto de Roma}

La amnistía, entendida como una alternativa de enfrentar el conflicto recurriendo a la paz, dejando de lado las acciones penales y jurídicas que se pudieran aplicar 
debido a la necesidad de reconstruir pacíficamente. En la actualidad, dentro de las negociaciones y acuerdos del gobierno con las Farc, la amnistía y el indulto se han visto representadas en la inmunidad en el derecho de cualquiera de las consecuencias legales penales por los errores cometidos en el pasado en un contexto político.

No obstante, en delitos de lesa humanidad como los perpetrados por las Farc, vale la pena considerar la pertinencia que tiene la amnistía e indulto frente a estos delitos, sacrificando lo promulgado en la justicia interna como en la externa, que para el caso particular sería lo estipulado en el Estatuto de Roma, el cual plantea que los crímenes más graves de trascendencia para la comunidad internacional en su conjunto no deben quedar sin castigo y que, a tal fin, hay que adoptar medidas en el plano nacional e intensificar la cooperación internacional para asegurar que sean efectivamente sometidos a la acción de la justicia.

El fenómeno de la impunidad está presente en nuestro país debido al conflicto armado que padecemos, y más si una de las formas para llegar a una negociación de paz con los grupos subversivos es logrando su reinserción a la sociedad civil, otorgándoles una amnistía o un indulto, según los cuales se extingue su responsabilidad penal ante la ley, pero sin perdonar el deber de resarcir los perjuicios ocasionados (Abello, 2005).

Esta misma problemática se desencadena en la relación que surge entre el derecho internacional y el derecho nacional, pues con la creación de órganos jurisdiccionales internacionales de carácter subsidiario, como la Corte Interamericana (Daza, 2014); o de carácter complementario, como la Corte Penal Internacional, se ha dotado al derecho internacional de juridicidad.

El estatuto pretende que los autores de crímenes de lesa humanidad no queden impunes, en este sentido dentro de los acuerdos de paz es necesario contemplar una amnistía condicionada. En la Sentencia C-695 nos afirma que:

Debe tenerse en cuenta que con frecuencia el constituyente y el legislador manejan con amplitud los conceptos de amnistía e indulto y de allí por qué se habla, por ejemplo, de indultos generales. Ello es así en cuanto los graves motivos de conveniencia pública pueden conducir a regulaciones constitucionales o legales que, en estricto sentido, no se atiene a la naturaleza de la amnistía o del indulto pero que son comprensibles en razón de los altos intereses que se hallan en juego (2002). 
De allí que existe lo promulgado por el Estatuto de Roma, cuyo fin primordial es evitar la impunidad así como prevenir delitos, la ley de amnistía y perdón pueden ser instrumentos tenidos en cuenta con el fin de tomar una decisión de la responsabilidad penal internacional de las violaciones graves y protección de los derechos fundamentales de las víctimas.

Sin embargo, es imposible no contemplar la posición del Estatuto de Roma y el establecimiento de la Corte Penal Internacional en decidir en si es posible conceder amnistías e indultos. A la luz de este instrumento internacional es confuso y aún no es claro sobre este asunto, ya que no tiene en cuenta la cuestión de si una amnistía nacional puede ser tratada como para abrir al procesamiento ante la Corte Penal Internacional.

De esta manera, ya una decisión nacional como lo sería la concesión de una amnistía o un indulto, tendría repercusiones internacionales que sin duda llegarían a la competencia de las cortes internacionales, donde se podría analizar la responsabilidad del Estado en el incumplimiento de sus obligaciones internacionales, y también podría someterse nuevamente al individuo amnistiado o indultado a un juicio de responsabilidad penal por sus actuaciones (Abello, 2005).

Así pues, ante los anteriores presupuestos se hace necesario contemplar el principio de proporcionalidad, el cual se enfoca en fundamentar los derechos primordiales desde el Derecho Constitucional, su objeto consiste en analizar la aplicación del principio en cuanto a criterio para determinar el contenido de los derechos fundamentales que pueden resultar vinculantes para el legislador (Bernal, 2007, p. 61).

El principio de proporcionalidad implica tres presupuestos básicos para su acción jurídica, el primero que se pretende a sí mismo como una decisión correcta, el segundo que pretende ser reconocido y considerado en la práctica constitucional y que finalmente aspira a su fundamentación. La proporcionalidad brinda los criterios necesarios para la determinación del contenido de los derechos fundamentales y para la fundamentación de decisiones de control de constitucionalidad. Este se define como: 
El principio de proporcionalidad sostiene que la acción militar es proporcional en la medida que el ataque a un objetivo militar ocasione bajas y daños civiles que no son excesivos en comparación al resultado global. Exige, por consiguiente, que los medios de combate resulten razonables, proporcionados y ajustados a la ventaja militar directa y concreta que se pretende obtener, incluyendo la prohibición de causar daños incidentales contra la población o bienes civiles, excluyendo toda forma de violencia excesiva o que no resulte indispensable para debilitar al adversario (González, 2007, p. 108).

El principio de proporcionalidad guarda equivalencia, correspondencia y equilibrio, se caracteriza por ser de carácter institucional, pues permite determinar la constitucionalidad tanto en la intervención o restricción de los poderes públicos sobre los derechos fundamentales (Becerra, 2012).

La proporcionalidad como principio constitucional del Derecho Internacional Humanitario permite que exista equilibrio entre las acciones que el Estado lleva a cabo en relación con la protección de los derechos humanos de las personas vinculadas al conflicto armado de manera directa o indirecta, así como el cumplimiento de sus fines y en cierta manera se puede relacionar directamente con la Ley de Amnistía que se plantea aplicar con los actores culpables de delitos de lesa humanidad como pueden representar sometimiento a la población a prácticas como el asesinato, el secuestro, el traslado forzoso de población, la desaparición forzada de personas, el desplazamiento forzado, el ataque generalizado contra la población civil, el terror, la destrucción de bienes y servicios etc. 


\section{Conclusión}

El Estatuto de Roma al ser un ente regulador a nivel internacional y con la potestad de poder intervenir en conflictos internos de los Estados, creado con el fin de combatir la impunidad de los crímenes más graves en contra de la raza humana, puede ejercer su jurisdicción complementaria sobre los crímenes de su competencia cometidos en desarrollo del conflicto armado colombiano, lo cual pondría en grave peligro la viabilidad jurídica de los procesos de paz si no se realiza una ponderación adecuada de los principios de justicia y paz, en la cual se cumpla con los parámetros internacionales sin obstaculizar la tan anhelada paz en nuestro país.

El estatuto de roma aprobaría una amnistía o indultos condicionados frente a los actores del conflicto armado, sumado a esto también condenas flexibles para los mandos medios y altos, teniendo en cuenta que no se busca la impunidad sino buscar justicia y no en sacrificio de la paz o de las víctimas (Becerra, 2012), de allí que sea necesario el modelo de priorización de casos todas estas acciones mediadas por el principio de proporcionalidad, el cual permite que exista equilibrio entre las acciones que el Estado lleva a cabo en relación con la protección de los derechos humanos de las personas vinculadas al conflicto armado de manera directa o indirecta, así como el cumplimiento de sus fines y en cierta manera se puede relacionar directamente con la Ley de Amnistía que se plantea aplicar con los actores culpables de delitos de lesa humanidad. 


\section{Referencias}

Abello, J. (2005). La Corte Penal Internacional, la protección de los derechos humanos y la salida negociada al conficto armado colombiano. (Monografía de grado). Universidad del Norte: Barranquilla.

Ambos, K. Y. (1999) El Estatuto de Roma de la Corte Penal Internacional. Revista de Derecho, (p. 32). Bogotá: Universidad Externado de Colombia.

Anuario Legis. (2009). Acto Legislativo n.o 2 de 2001. Bogotá: Publicaciones Electrónicas Legis Editores S. A.

Arellano, F. (s.f.). Contenido Jurídico. Recuperado de http://www.conteudojuridico.com. $\mathrm{br} / \mathrm{pdf} / \mathrm{cj034090.pdf}$

Becerra, O. (8 de febrero de 2012). El principio de la proporcionalidad. Recuperado de http:// blog.pucp.edu.pe/blog/orlandobecerra/2012/02/18/el-principio-de-proporcionalidad/

Bernal, C. (2007). El principio de proporcionalidad y los derechos fundamentales. Madrid: Centro de estudios políticos y constitucionales.

Briceño de Valencia, T. (2000). Diccionario técnico jurídico. Bogotá: Ediciones Gráficas Ltda.

Centro Nacional de Memoria Histórica. (2013) ;Basta ya! Colombia: memorias de guerra y dignidad (resumen). Bogotá: Imprenta Nacional de Colombia.

Congreso de Colombia. (31 de julio de 2012). Por medio del cual se establecen instrumentos jurídicos de justicia transicional en el marco del artículo 22 de la constitución política y se dictan otras disposiciones. Acto legislativo. Recuperado de https://www.ictj.org/ictj/docs/ Marco_juridico/ACTO_LEGISLATIVO_01-31JULIO2012.pdf

Cortes, S. (2016). Derechos humanos en las políticas de paz y posconflicto en Colombia. Revista Via Inveniendi et Iudicandi, 11(1), 129-145. Recuperado de https://revistas. usantotomas.edu.co/index.php/viei/article/view/2926

Corte Constitucional. (28 de agosto de 2002). Sentencia C-695-02. [M.P. Jaime Córdoba Triviño].

Corte Constitucional. (1 de junio de 2014). Sentencia C-577. [M.P. Gloria Stella Ortiz Delgado].

Corte Constitucional. (30 de julio de 2002). Sentencia C-578. [M.P. Eduardo Muñoz].

Corte Constitucional. (28 de agosto de 2013). Sentencia C-579. [M.P. Mauricio González Cuervo].

Chernick, M. (1 de octubre de 1996). Aprender del pasado: breve historia de los procesos de paz en Colombia (1982-1996). Recuperado de http://colombiainternacional.uniandes.edu. co/view.php/241/view.php 
Daza, M. (9 de febrero de 2014). ¿Es posible conceder amnistias e indultos a la luz del Estatuto de Roma en el marco del conflicto armado colombiano? Recuperado de https://derechopublicomd.blogspot.com.co/2014/02/este-breve-articulocorresponde-lo-que.html

Delvecchio, G. (1959). El derecho internacional humanitario. Barcelona: Casa Editorial Urgel. Fernández, F. V. (2015). El derecho internacional ante el conflicto armado. Valencia: Tirant to Blanch.

Fernández, F. V. (2015). Nacimiento de las guerrillas revolucionarias. Recuperado de http:// www.colombia.com/actualidad/especiales/dialogos-de-paz/antecedentes/

Giraldo, J. (1 de marzo de 2015). Aportes sobre el conficto armado en Colombia, su persistencia y sus impactos. Colombia. Recuperado de https://www.centrodememoriahistorica.gov. co/descargas/comisionPaz2015/GiraldoJavier.pdf

González, D. (2007). Normas básicas y principios fundamentales de protección a las personas en el Derecho Internacional. Washington: Departamento de Asuntos Internacionales de la OEA.

Guerrero, K. A. (2006). El Estatuto de Roma de la Corte Penal Internacional. Bogotá: Universidad Externado de Colombia. Revista de Derecho.

Gutiérrez, L. M., y Rodríguez, J. (2013). Una comisión de la verdad en el modelo colombiano de justicia transicional: aproximación a través de la historia reciente y la experiencia comparada. Jurídicas, 10(2), 40-60. Manizales: Universidad de Caldas.

Huila, D. E. (18 de septiembre de 2016). Proceso de paz en Colombia. Recuperado de http://www.diariodelhuila.com/proceso-de-paz/procesos-de-paz-en-colombia -cdgint 20160926155028132

Legis. (2014). Constitución Política de Colombia. Bogotá: Editorial Legis.

Legis. (2 de septiembre de 2014). Ley de víctimas y restitución de tierras. Bogotá: Editorial Legis.

LLorente, M. (1999). Reconocer la guerra para construir la paz. Bogotá: Universidad de Los Andes.

LLorente, M., Escobedo, R., Echandía, C., y Rubio, M. (23 de septiembre de 2002). Violencia homicida y estructuras criminales. Sociologías, Porto Alegre, (8), 172-205. Recuperado de http://www.scielo.br/pdf/soc/n8/n8a08.pdf

López, C., y Cueter, N. (2016) ¿̇ंPor qué Santos si pudo dialogar con las Farc? Bogotá: Redacción E1 Tiempo. Recuperado de http://www.eltiempo.com/politica/proceso-de-paz/ procesos-de-paz-en-colombia-44168

Ministerio de Justicia. (2014). La justicia transicional vista desde las regiones. Reporte del ejercicio de participación social para la formulación de nuevos mecanismos de justicia transicional en Colombia. Bogotá, Colombia: Arte Impreso S.A.S. 
Molano, A. (2010). Fragmentos de la bistoria del conflicto armado en Colombia (1920-2010). Recuperado de http://www.altocomisionadoparalapaz.gov.co/mesadeconversaciones/PDF/ fragmentos-de-la-historia-del-conflicto-armado-1920-2010-1447167631-1460380435. pdf

Naciones Unidas. (25 de abril de 2007). Centro de Información de las Naciones Unidas. Recuperado de http://www.cinu.org.mx/temas/Derint/cpi.htm\#importancia

Pardo, R. (2004). La historia de las guerras. Bogotá, Colombia: Talleres de imprelibros S. A.

Paz, A. C. (13 de novimebre de 2013). Preguntas y respuestas. Marco jurídico para la paz. Recuperado de http://www.altocomisionadoparalapaz.gov.co/desarrollos-legistlativos-paz/ marco-juridico-para-la-paz/Documentos\%20compartidos/marco_juridico_para_la_paz. pdf

Ramelli, A. (2008). La constitución colombiana y el derecho internacional humanitario. Bogotá: Universidad Externado de Colombia.

Rivera, H. (20 de mayo de 2014). Conversatorio sobre penas alternativas y sanaciones extrajudiciales en Colombia: más allá de la cárcel. Recuperado de https://www.ictj.org/es/news/ conversatorio-penas-alternativas-sanciones-extrajudiciales-colombia

Stewart, J. (2015). Conferencia inaugural. Foro: la justicia transicional en Colombia y el papel de la Corte Penal Internacional. Bogotá.

Uprimmy, R. (2005) ¿̇usticia transicional sin transición? Verdad, justicia y reparación para Colombia. Bogotá: Ediciones Antrophos.

Valencia, A. (2007). Derecho internacional bumanitario. Conceptos básicos infracciones en el conflicto armado colombiano. Bogotá: Oficina Alto Comisionado de Naciones Unidas para los derechos humanos.

Vargas, A. (15 de junio de 2013). Golpe militar y fin de la violencia bipartidista. Recuperado de https://www.elcolombiano.com/historico/golpe_militar_y_fin_de_la_violencia _bipartidista-NBEC_246821 